\title{
EXAMINING THE STUDENTS' UNDERSTANDING LEVEL TOWARDS THE CONCEPTS OF SPECIAL THEORY OF RELATIVITY
}

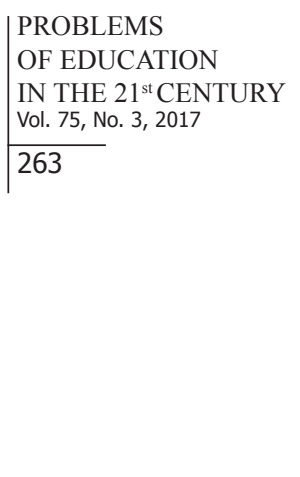

Özgür Özcan

Hacettepe University, Ankara, Turkey

E-mail: ozcano@hacettepe.edu.tr

\begin{abstract}
Special theory of relativity is one of the difficult subjects of physics to be understood by the students. The current research designed as a qualitative research aim to determine the pre-service physics teachers' understanding level and the alternative conceptions about three core concepts of special theory of relativity, such as time dilatation, length contraction and reference frames. The data were collected through semi structured interviews and were analyzed by using content analysis. At the end of the analysis process the understanding level of the students was determined to be "complete understanding", "incomplete understanding" and "misunderstanding". In order to achieve this, the students' conceptual frameworks based on the operational definitions made by the students were determined firstly. The findings obtained in this research indicate that high school teachers as well as university instructors should take special care with some points in the teaching of the subjects related with special theory of relativity. This research might be useful to other studies to be done in the future, especially for investigating the students' mental models related to special theory of relativity.
\end{abstract}

Key words: Length contraction, reference frames, special relativity, time dilatation, understanding level.

\section{Introduction}

Special theory of relativity is one of the important topics of modern physics. The theory, whose foundations were laid in the early 20th century, has been influential not only in the field of physics but also in many fields such as philosophy. With this theory, this has a conception quite different from that of classical physics; perspectives of spatial and temporal phenomena have completely changed. The change has in turn led to learning difficulties in relation to the topic. Therefore, learning difficulties relevant to the issue have been studied by researchers with deep interest. Because the concepts of the special theory of relativity are the concepts which cannot directly be observed in daily life, they are difficult for students to learn. Nevertheless, the correlations between concepts students learn and the concepts they learn by identifying with their daily life should be analyzed. Such analyses could be useful in reasoning required for teaching advanced subjects (Scher, Shafter \& Vokos, 2001). A study carried out by Villani and Pacca (1987) showed that students had serious problems in understanding the concepts of special theory of relativity. According to the results of this research many students showed a variety of inconsistencies in these concepts. On the other hand, many of the students in this study were only able to solve the problems using absolute notions of space and time.

The number of studies concerning the special theory of relativity is quite small (Scher et al., 2001; Scher, Shafter \& Vokos, 2002; Scher, 2001; Selçuk, 2011; Özcan, 2011). The majority of them are related with Galilean relativity (Panse, Ramamdas \& Kumar, 1994; Ramadas, Barve \& Kumar, 1996). According to Panse et al (1994) and Ramadas et al (1996), reference frames are only limited by physical size for many students. Besides, an object can 
Özgür ÖZCAN. Examining the students' understanding level towards the concepts of special theory of relativity

PROBLEMS

OF EDUCATION

IN THE $21^{\text {st }}$ CENTURY Vol. 75, No. 3, 2017

264

of the frames of reference by leaving its environment. Saltiel and Malgrande (1980) identified learning difficulties students encountered in terms of relative motion. Accordingly, many students described the motion of objects as an "intrinsic" property rather than a size measurable according to the frames of reference. Additionally, students classified movement into two: "real movement" in which dynamic effects were available, and "apparent movement" which was not physical and which was actually an optical illusion. Villani and Pacca (1987) found that university students' reasoning about the special theory of relativity was similar to the one observed in studies concerning Galilean relativity. A case study conducted by Hewson (1982) found that students had "metaphysical" thoughts in relation to the special theory of relativity. Here, students described relative effects such as length contraction and time dilatation as "distortion in perception". Posner et al (1982) also reached similar conclusions.

The concepts examined in this research occupy a very important place in relative motion. For this reason, lessons in which the special theory of relativity is taught start by teaching reference frames where measurements of location and time in which observers are available are made. Fundamental concepts such as reference frames, time dilatation, and length contraction are on the basis of each subject in the special theory of relativity. Understanding these concepts well is very important in the teaching of the subject. Determining the kinematic magnitude in systems, and having an idea of the measurements made by different observers can be explained with the use of reference frames moving with the constant velocity relatively to each other. Firstly, comprehension difficulties student experience for the relevant concepts should be identified in determining the position in relation to a topic, in measuring the time, and in discussing under what circumstances synchronism is possible.

The fact that students have difficulties in understanding the concepts related to the special theory of relativity can be connected with the abstract nature of these concepts. That is to say, students can have difficulty in associating the concepts of this subject with their prior knowledge. This hinders meaningful learning and causes alternative conceptions about the subject to emerge. This research sets out to determine pre-service physics teachers' understanding level about the important concepts of special theory of relativity and the probable alternative conceptions about those concepts. It is commonly known that the students interpret and make sense of concepts via knowledge which is considered scientifically correct or with non-scientific knowledge conflicting with this knowledge (Taber, 1994). For this reason, this research seeks answers to the following research questions so as to fill the gap in current literature related to this subject and to make contributions to the research area of physics education.

(1) What are the understanding levels of the students towards the concepts of reference frames, time dilatation and length contraction?

(2) What are the alternative conceptions of students about these concepts?

\section{Methodology of Research}

This research is conducted by using case study which is a qualitative research design. Qualitative research aims to exhibit individuals' thoughts and behaviours in a realistic and holistic manner (Yıldırım \& Şimşek, 2008). This research was performed in the fall semester of 2015-2016 academic year with the participation of volunteering pre-service physics teachers. The data were collected through semi-structured interviews and then were analysed by using content analysis method.

\section{Sample of Research}

The sample of research was composed of 14 pre-service physics teachers enrolled at a state university in Ankara. Purposeful sampling method was used to determine the participants in this research. The course achievement of the students was used as criteria of determining the 
participants, since all of them had taken and passed the mechanics course containing the subject of the special theory of relativity. Six of the participants were male whereas seven were female, and they were in the 21-24 age range. The participants were informed about the research and voluntary participation was ensured. They were also told that the research results would be used for scientific purposes.

\section{Data Collection Tool and Analysis}

The data for the research were collected through semi-structured interviews. All interviews were video recorded. The data, collected through semi-structured interviews, were firstly put to computer. The data were then encoded through content analysis method, and the codes were determined. Subsequently, the initial categories (understanding levels) were composed according to the codes. All three concepts under research were analyzed by following the same procedures and were classified under three different categories. The categories were 'complete understanding', 'incomplete understanding', and 'misunderstanding', respectively. Following the analyses performed again by another researcher according to the above mentioned levels of comprehension, $90 \%$ fit was attained. Then, in consequence of analysis made by the two researchers, full agreement was reached in relation to the categories.

\section{Results of Research}

We determined the students' understanding levels and the possible alternative conceptions about the important concepts related to the special theory of relativity. In the light of the findings of the content analysis performed, the number of students at each understanding level is shown in Table 1. Also, the examples of students' alternative conceptions and the explanations made by students about three concepts are presented below.

\section{Table 1. Students' understanding levels}

\begin{tabular}{lc}
\hline Understanding Level (CU, IU, MU)* & Number of students (N) \\
\hline Complete Understanding & 6 \\
\hline Incomplete Understanding & 3 \\
\hline Misunderstanding & 5 \\
\hline *CU: Complete Understanding, IU: Incomplete Understanding, MU: Misunderstanding
\end{tabular}

\section{Complete Understanding $(C U)$}

In consequence of the analyses performed, 6 out of 14 participants were found to be in this category. Students in this category gave responses appropriate to the scientific descriptions related with the three concepts. That is to say, it may be said that the operational definitions students employed for the questions on length contraction, time dilatation, and reference frames were parallel to scientific knowledge. Students who had stressed that relative effects arose at high speed said that they could not observe those effects in daily life. Students in this category stated that the action of time dilatation could easily be measured in sub-atomic particles in the laboratory. A few students emphasized that time contraction was observed in the measurement of decay time and life time of some elementary particles. In addition to that, some examples given by the students in this category were also remarkable. These examples were about the micro-scale cracks that could occur in supersonic aircrafts and about the time dilatation occurred in events at high speed. In this context, the answers about the length contraction and time dilatation were also in parallel to scientific facts. That is, these explanations made 
Özgür ÖZCAN. Examining the students' understanding level towards the concepts of special theory of relativity

PROBLEMS

OF EDUCATION

IN THE $21^{\text {st }}$ CENTURY Vol. 75, No. 3, 2017

266

by the students in this category could be accepted as scientifically correct answers. Only four of six participants talked of only examples related with length contraction. They pointed out that length contraction would occur in the direction of movement, but that components at a right angle according to the movement would not be affected. Those students wrote down Lorentz Transformations and supported their explanations by using mathematical statements. The other two students used only examples related with time dilatation and reference frames. Explanations through the example for actions happening synchronically were remarkable in relation to explanations about reference frames. For instance, students in this category said that time difference would be zero between two synchronic explosions happening for an observer on a fast train while there would be time difference for an observer outside the train. The students supported their explanations by writing down the right equations. On the other hand, the students whose understanding level was determined as "complete understanding" had no alternative conceptions, because their operational definitions about the special theory of relativity concepts were scientifically acceptable according to their explanations.

\section{Incomplete Understanding (IU)}

The analyses performed demonstrated that 3 of 14 students were in the category of "incomplete understanding". Students in this category made explanations not fully overlapping with scientific definitions for all three concepts. In other words, it may be said that the operational definitions students used in their responses to the questions about length contraction, time dilatation and reference frames were not in parallel to scientific knowledge. Besides, it may also be stated that there were instances of wrong intuitive understanding. For instance, all three students said that length contraction could occur both in vertical and horizontal directions. In other words, all of the students in this category stated in their explanations and in their equations that length contraction could also occur in vertical direction to the motion. The role played by observers could not be identified very well here. Students having this mistake could not offer completely correct explanations for the other two concepts (namely, time dilatation and reference frames), either. All students having conceptual and mathematical difficulties in the special theory of relativity made incorrect inferences. In this case, students may be said to have incomplete scientific knowledge in relation to these concepts and that consequently they had wrong intuitive understanding in a similar manner. It was found, on the other hand, that the students in this category had some alternative concept. The following alternative concepts were determined in relation to observers moving relatively at constant speed according to each other in reference frames.

$\boldsymbol{S t}_{2}$ : Measurements made within two reference frames moving relative to each other are not dependent on observers. The measurement results of observers who are in both reference frames are the same.

$\boldsymbol{S t}_{7}:$ An observer is always outside the reference frames.

Some of the knowledge stated by the students in relation to time dilatation can again be considered among alternative conceptions. For instance,

$\mathbf{S t}_{\mathbf{7}}$ : Time dilatation is something that does not exist in reality. I believe it is just an optical illusion.

$\mathbf{S t}_{\mathbf{1 3}}$ : Time dilatation happens only in moving reference frames. It does not happen in stationary reference frames. 
As it is clear from the above mentioned statements, students have alternative conceptions about time dilatation. In other words, they see time dilatation as an optical illusion rather than a scientific reality. On the other hand, it was stated by students that time dilatation cannot occur in stationary reference frames. The cause for this situation is that students have alternative conceptions about the relativity of motion. That is to say, students (three out of 14 students) have incomplete or incorrect knowledge about this subject.

\section{Misunderstanding (MU)}

All of the students in this category responded the questions incorrectly both conceptually and mathematically about three concepts. The analyses showed that five of the 14 students were in the category of "misunderstanding". The students in this category made explanations which were not in parallel to scientific definitions. That is to say, it may be stated that students' operational definitions in their responses to the questions about length contraction, time dilatation and frame references did not overlap with scientific knowledge. The most remarkable finding in the responses of students in this category was to relate the special theory of relativity with mass change. All of the students in this category said that the mass of an object moving at high speed would increase. The excepts of alternative conceptions that students stated related to this category were given below;

$S_{\mathbf{g}}:$ The mass of an object will change when it moves near with the speed of light. I have seen such type of exercises in the textbooks.

$S_{\mathbf{g}}:$ Actually there is no length contraction. It's just an optical illusion.

$S_{11}:$ The laws of physics may vary from one reference frame to another moving with constant velocity relative to each other. The measurement results cannot be the same in both reference frames.

As we see from the answers of the students given above, the students have interesting alternative conceptions about the concepts of special theory of relativity. The students in this category stated that the law of physics would change depending on the reference frames moving with constant velocity relative to each other. Actually, the students used the knowledge related to the invariance of the physics law and the measurement results of the physical quantities interchangeably. These two concepts are quite different from each other. Of course the laws of physics are invariant (i.e., identical) in all non-accelerating reference frames, whereas the measurement results of the physical quantities may change from one reference frame to another that are moving with constant velocity relative to each other.

\section{Discussion}

This research made an attempt at determining pre-service physics teachers' understanding levels concerning the special theory of relativity. Thus, three understanding levels were identified: "complete understanding", incomplete understanding", and "misunderstanding". Pre-service teachers explained the concepts by means of such concepts as 'reference frames', 'mass', 'time', and 'actions and observers'. The concept of time dilatation was generally explained with examples for the decay of particles and for synchronism. Operational definitions used by pre-service teachers in the category of complete understanding were consistent with scientific knowledge, whereas those used by pre-service teachers in the other categories were not consistent with scientific knowledge. It was found that teachers in the category of "misunderstanding" in particular had wrong intuitive understanding. Although pre-service teachers in the category of "incomplete understanding" made conceptually correct definitions, 
Özgür ÖZCAN. Examining the students' understanding level towards the concepts of special theory of relativity

PROBLEMS

OF EDUCATION

IN THE $21^{\text {st }}$ CENTURY Vol. 75, No. 3, 2017

268

had difficulty in making mathematical explanations. Two pre-service teachers in this category, on the other hand, said that observers acted in accordance with the reference frames in which actions occurred. That is to say, those pre-service teachers perceived the frame of observation as a closed place which they could leave and go outside. A similar result was also remarkable in previously performed research studies (Panse, Ramadas \& Kumar, 1994; Ramadas et al., 1996). Explanations offered by pre-service teachers in relation to the concepts related with length contraction also showed that they had difficulties in comprehension. The misunderstanding that pre-service teachers saying that components at a right angle with the movement would be exposed to length contraction had was detected by Selçuk (2011). The reason for why pre-service teachers thought so might be their wrong intuitive understanding about the concepts of the special theory of relativity.

An important point that needs consideration, on the other hand, is that students use scientific and unscientific knowledge fragments together in their explanations on the concepts of special relativity. That is to say, pre-service teachers make connections between knowledge fragments of these two types, and thus make explanations. Therefore, the inappropriate use of these knowledge structures related with the concepts of the subject has caused the emergence of unscientific explanations and definitions. In other words, those explanations which were not identical with scientific knowledge were coded as incomplete understanding in the section of findings. These fragments of knowledge appearing in the minds of students in relation to the concepts formed barriers in front of their meaningful learning. In contrast to this situation, the explanations of the concepts made by students whose understanding levels were found to be complete understanding were both scientific and coherent. That is, there was a coherent structure in their explanations. For this reason, the understanding levels of students who used scientific approaches in their explanations of the above mentioned concepts of special relativity were quite different than those who did not make scientific explanations.

\section{Conclusion and Implications for Teaching}

This research determined three different understanding levels about the important concepts of special theory of relativity. An important factor distinguishing the understanding levels from one another was whether or not the explanations about the concepts were scientific. That is to say, a classification was made according to whether or not the explanations made by pre-service physics teachers in relation to the concepts were scientifically correct or incorrect. In consequence of the classification, it was found that there were six students in the category of "complete understanding", three students in the category of "incomplete understanding", and five students in the category of "misunderstanding". It may be said that the operational definitions offered by students in the category of "complete understanding" were more scientific than those students in the other categories. On the other hand, it was also found that the students in the category of "complete understanding" did not have alternative conceptions but that the students at the other understanding levels had several alternative conceptions.

The findings obtained in this research indicate that high school teachers as well as university instructors should take special care with some points in the teaching of subjects related with special relativity. Content or contexts to facilitate students' learning of scientific knowledge in relation to concepts such as reference frame, time and length shortening should be prepared. Advance organizers such as concept maps or conceptual frameworks should be used at this point. Thus, the advance organizers facilitate students to make connections between concepts. Besides, such a rich course content will trigger students to make scientific explanations for the concepts. Determining students' prior knowledge is also important. Their prior knowledge in relation to the subject should be determined by using concept maps before starting a lesson. At the end of each subject, course books should give a list of the important concepts, and include a sample concept map containing those concepts. In addition to that, emphasis should be laid on connections between the concepts in course books or in classes. 
This will assure that students make the connections between concepts in a coherent way, and thus it will help them to organize the knowledge. Individuals' having scientific knowledge in relation to concepts will encourage the development of complex organized knowledge about the phenomena. This, in turn will play a key role in the occurrence of meaningful learning.

\section{Note}

An earlier version of this research was presented at WCES 2016 - 8th World Conferences on Educational Sciences in February 2016, Madrid, Spain.

\section{References}

Hewson, P. W. (1982). A case study of conceptual change in special relativity: The influence of prior knowledge in learning. European Journal of Science Education, 4, 61-78.

Panse, S., Ramadas, J., \& Kumar, A. (1994). Alternative conceptions in Galilean relativity: Frames of reference. International Journal of Science Education, 16 (1), 63-82.

Posner, G. J., Strike, K. A., Hewson, P. W., \& Gertzog, W. A. (1982). Accommodation of a scientific conception: Toward a theory of conceptual change. Science Education, 66, 211-227.

Ramadas, J., Barve, S., \& Kumar, A. (1996). Alternative conceptions in Galilean relativity: Inertial and non - inertial observers. International Journal of Science Education, 18 (5), 615-630.

Saltiel, E., \& Malgrange, J. L. (1980). 'Spontaneous' ways of reasoning in elementary kinematics. European Journal of Physics, 1, 73-80.

Scherr, R. E. (2001). An investigation of student understanding of basic concepts in special relativity (PhD Thesis). University of Washington, Washington.

Scherr, R. E., Shaffer, P. S., \&Vokos, S. (2001). Student understanding of time in special relativity: Simultaneity and reference frames. American Journal of Physics, Physics Education Research Supplement, 69 (S1), 24-35.

Scherr, R. E., Schaffer, P.S., \& Vokos, S. (2002). The challenge of changing deeply held student beliefs about the relativity of simultaneity. American Journal of Physics, 70, 1238-48.

Selçuk, G. S. (2011). Addressing pre-service teachers' understandings and difficulties with some core concepts in the special theory of relativity. European Journal of Physics, 32, 1-13.

Özcan, Ö. (2011). Fizik öğretmen adaylarının özel görelilik kuramı ile ilgili problem çözme yaklaşımları [Pre-service physics teachers' problem solving approaches in special theory of relativity]. Hacettepe University Journal of Education, 40, 310-320.

Villani, A., \& Pacca, L. (1987). Students' spontaneous ideas about the speed of Light. International Journal of Science Education, 9 (1), 55-66.

Yıldırım, A., \& Şimşek, H. (2008). Sosyal bilimlerde nitel araştırma yöntemleri [Qualitative research methods in the social sciences] (6. Baskı). Ankara: Seçkin Yayıncılık.

Received: May 03, 2017

Accepted: June 25, 2017

Özgür Özcan

$\mathrm{PhD}$, Associate Professor, Hacettepe University, Faculty of Education, Mathematics and

Science Education Department, 06800, Beytepe, Ankara, Turkey.

E-mail: ozcano@hacettepe.edu.tr 